\title{
Erythrocytic cation transport receptor numbers and activity in pregnancies complicated by essential hypertension and pre-eclampsia
}

\author{
J K ARONSON, M P MOORE, C W G REDMAN, C HARPER
}

\begin{abstract}
Various functions of erythrocytic cation transport were studied in normotensive and hypertensive pregnancy (women with pre-eclampsia and essential hypertension). The results showed that in pregnancy there is an increase in the number of erythrocytic glycoside binding sites accompanied by a proportional increase in the active inward transport of rubidium (used as a substitute for potassium). There was no evidence of an effect of pregnancy on intraerythrocytic sodium concentrations. These changes were apparently entirely attributable to pregnancy and not affected by pre-eclampsia or essential hypertension.

It is suggested that these alterations indicate an adaptive increase in sodium pump numbers and activity secondary to a tendency for the intraerythrocytic sodium concentration to rise during pregnancy and compensating for that tendency.
\end{abstract}

\section{Introduction}

Several abnormalities of cation transport have been described in the erythrocytes and leucocytes of patients with essential hypertension. ${ }^{1}$ In pregnancy hypertension may occur either as an already existing condition or as a manifestation of pre-eclampsia. We have therefore studied several different functions of cation transport in the erythrocytes of women with and without hypertension in pregnancy to see whether there are abnormalities and, if so, to what extent these might be attributable to pregnancy and to what extent attributable to hypertension. We have reported briefly on our findings elsewhere. ${ }^{2}$

\section{Patients and methods}

We studied 18 women with pre-eclampsia and 15 with essential hypertension. For each woman with pre-eclampsia or essential hvpertension a normotensive woman with an uncomplicated pregnancy was chosen to match for parity and for gestation to within one week. Each woman was studied while pregnant at some time after the 28 th week of gestation and again at six weeks post partum.

Criteria for pre-eclampsia were: a systolic blood pressure $\geqslant 140 \mathrm{~mm} \mathrm{Hg}$ and diastolic pressure $\geqslant 90 \mathrm{~mm} \mathrm{Hg}$ during the third trimester; a rise in diastolic blood pressure of at least $25 \mathrm{~mm} \mathrm{Hg}$

MRC Unit and University Department of Clinical Pharmacology, Radeliffe Infirmary, Oxford OX2 6HE

J K ARONSON, DPHIL, MRCP, clinical reader (Wellcome lecturer) and honorary consultant in clinical pharmacology

C HARPER, technician

Nuffield Department of Obstetrics and Gynaecology, John Radcliffe Hospital, Oxford OX3 9DU

M P MOORE, MB, BS, overseas research fellow of the Medical Research Council of New Zealand

C W G REDMAN, MB, FRCP, lecturer and honorary consultant in obstetric medicine

Correspondence to: Dr J K Aronson. compared with the first blood pressure recorded during pregnancy (before 20 weeks of gestation in all cases); and persistent proteinuria of at least ++ on Albustix testing.

The women with essential hypertension had diastolic blood pressures $\geqslant 90 \mathrm{~mm} \mathrm{Hg}$ or systolic blood pressures $\geqslant 140 \mathrm{~mm} \mathrm{Hg}$, without treatment, at the time of booking before 20 weeks of gestation. This group included nine women who had received treatment for essential hypertension before pregnancy but whose treatment had been withdrawn when pregnancy was diagnosed. In two instances antihypertensive drugs (methyldopa and atenolol) were later reintroduced.

Cation transport measurements on the women's erythrocytes were carried out as follows using methods detailed elsewhere ${ }^{34}:(a)$ the maximal ability of the erythrocyte membranes to bind ${ }^{3} \mathrm{H}$-digoxin specifically in vitro was taken as a measure of the number of $\mathrm{Na}^{+}, \mathrm{K}^{+}-$ adenosine triphosphatase cation transport sites on the membranes; (b) the ability of the erythrocytes to transport rubidium- $86\left({ }^{86} \mathrm{Rb}\right.$ uptake) was taken as a measure of the activity of $\mathrm{Na}^{+}, \mathrm{K}^{+}$-adenosine triphosphatase (rubidium functioning as a substitute for potassium); (c) the intraerythrocytic sodium concentration was measured.

Statistical analyses were made using Student's paired or unpaired $t$ test, as appropriate.

\section{Results}

\section{PATIENT CHARACTERISTICS}

Age and gestation at the time of sampling did not differ among the groups (table I). Ten of the 18 women with pre-eclampsia and five of the 15 with essential hypertension were primiparous.

Table II gives the systolic, diastolic, and mean arterial pressures of the women with essential hypertension and pre-eclampsia. "Booking" pressures were those taken at the first clinic attendance before 20 weeks; "study" pressures were the maximum pressures taken no more than five days before blood sampling; "postpartum" pressures were those recorded six weeks after delivery. In both groups of women the pressures at the time of study were significantly higher than those at booking and six weeks after delivery ( $p<0.005$ or better in all cases). The women with essential hypertension had significantly higher pressures than the women who developed pre-eclampsia both at booking and after delivery ( $p<0.001$ in all cases), but there were no differences in the pressures taken at the time of study.

\section{CATION TRANSPORT MEASUREMENTS}

Figure 1 shows the maximal erythrocytic ${ }^{3} \mathrm{H}$-digoxin binding and ${ }^{86} \mathrm{Rb}$ uptake and the intraerythrocytic sodium concentrations in the two groups of hypertensive women compared with their respective matched normotensive controls. Figure 2 gives these measurements for the pregnant women compared with their own postpartum values.

There was no difference in respect of any of the measurements

TABLE I-Age and gestation at time of study during pregnancy. Figures are medians (ranges in parentheses)

\begin{tabular}{lcc}
\hline Group & Age (years) & $\begin{array}{c}\text { Gestation } \\
\text { (weeks, days) }\end{array}$ \\
\hline Pre-eclampsia $(n=18)$ & $25(17-36)$ & $33,5(28,1-38,4)$ \\
Matched controls & $24(17-30)$ & $33,3(28,3-38,0)$ \\
Essential hypertension $(n=15)$ & $28(20-32)$ & $34,4(28,2-37,2)$ \\
Matched controls & $25(17-34)$ & $34,5(28,5-37,0)$ \\
\hline
\end{tabular}


between the normotensive controls and either the pre-eclamptic women or those with essential hypertension. After delivery, however, ${ }^{3} \mathrm{H}$-digoxin binding and ${ }^{86} \mathrm{Rb}$ uptake fell significantly in all cases. By contrast, there was no change at all in the intraerythrocytic sodium concentrations after delivery.

In all three groups of women there was a significant correlation between ${ }^{3} \mathrm{H}$-digoxin binding and ${ }^{86} \mathrm{Rb}$ uptake both before and after delivery $(r=0.49 ; p<0.01$ for the combined groups). There was no relation, however, between either of these measurements and the intraerythrocytic sodium concentration in any group.

\section{Discussion}

Our data suggest that during pregnancy there is increased activity of $\mathrm{Na}^{+}, \mathrm{K}^{+}$-adenosine triphosphatase (as assessed by the inward transport of rubidium) due to an increase in the quantity of $\mathrm{Na}^{+}, \mathrm{K}^{+}$-adenosine triphosphatase present in the cell membrane (as assessed by specific ${ }^{3} \mathrm{H}$-digoxin binding). The increase in the amount of $\mathrm{Na}^{+}, \mathrm{K}^{+}$-adenosine triphosphatase was proportional to the increase in its activity. In other words, the activity of each site was not changed during pregnancy. We did not measure the affinity of binding and so cannot say whether there was also altered affinity of $\mathrm{Na}^{+}, \mathrm{K}^{+}$-adenosine triphosphatase for digoxin. The data also suggest that these changes in $\mathrm{Na}^{+}, \mathrm{K}^{+}$-adenosine triphosphatase function are not affected by or related to blood pressure, since the results in the two hypertensive groups of women were indistinguishable from those in the non-hypertensive women.

Despite the increase in numbers of digoxin binding sites and the increase in pump activity the intraerythrocytic sodium concentration remained unchanged during pregnancy. Since an increase in pump activity would be expected to lead to a

TABLE II-Systolic, diastolic, and mean arterial blood pressures ( $\mathrm{mm} \mathrm{Hg}$ ) at different times during study. Values are means [SD in square brackets]

\begin{tabular}{|c|c|c|c|}
\hline Group & "Booking" pressure & “Study" pressure & Postpartum pressure \\
\hline $\begin{array}{l}\text { Pre-eclampsia } \\
\text { Essential hypertension }\end{array}$ & $\begin{array}{l}116.9[14 \cdot 6](\mathrm{n}=17) \\
151.5[16 \cdot 9](\mathrm{n}=14) \dagger\end{array}$ & $\begin{array}{l}\text { ure } \\
164 \cdot 1[16 \cdot 5](n=18)^{*} \\
161 \cdot 4[11 \cdot 2](n=15)^{*}+\end{array}$ & $\begin{array}{l}123 \cdot 3[11 \cdot 2](n=16) \\
142 \cdot 9[15 \cdot 7](n=13)+\end{array}$ \\
\hline $\begin{array}{l}\text { Pre-eclampsia } \\
\text { Essential hypertension }\end{array}$ & $\begin{array}{l}\text { Dias } \\
70 \cdot 6[8 \cdot 3](n=17) \\
87 \cdot 5[9 \cdot 6](n=14) \dagger\end{array}$ & $\begin{array}{l}112 \cdot 1[11 \cdot 5](n=18)^{*} \\
103 \cdot 2[7 \cdot 2](n=15)^{*}\end{array}$ & $\begin{array}{l}79 \cdot 1[10 \cdot 4](n=16) \\
92.5[5 \cdot 7](n=13) \dagger\end{array}$ \\
\hline $\begin{array}{l}\text { Pre-eclampsia } \\
\text { Essential hypertension }\end{array}$ & $\begin{array}{c}\text { Mean arterial pressure } \\
85 \cdot 9[8 \cdot 6](n=17) \\
108 \cdot 7[8 \cdot 0](n=14)+\end{array}$ & $\begin{array}{c}+(\text { systolic-diastolic }) / 3) \\
130 \cdot 2[12 \cdot 0](\mathrm{n}=18)^{*} \\
122 \cdot 2[5 \cdot 3](\mathrm{n}=15)^{*}\end{array}$ & $\begin{array}{r}94 \cdot 7[10 \cdot 0](n=16) \\
109 \cdot 3[8 \cdot 2](n=13)+\end{array}$ \\
\hline
\end{tabular}

* Different from booking and postpartum pressures $(\mathrm{p}<0.005$ or better).

+ Different from corresponding pre-eclamptic pressures $(p<0.001)$
$\ddagger$ Different from booking pressure by paired test of 14 sets of data.

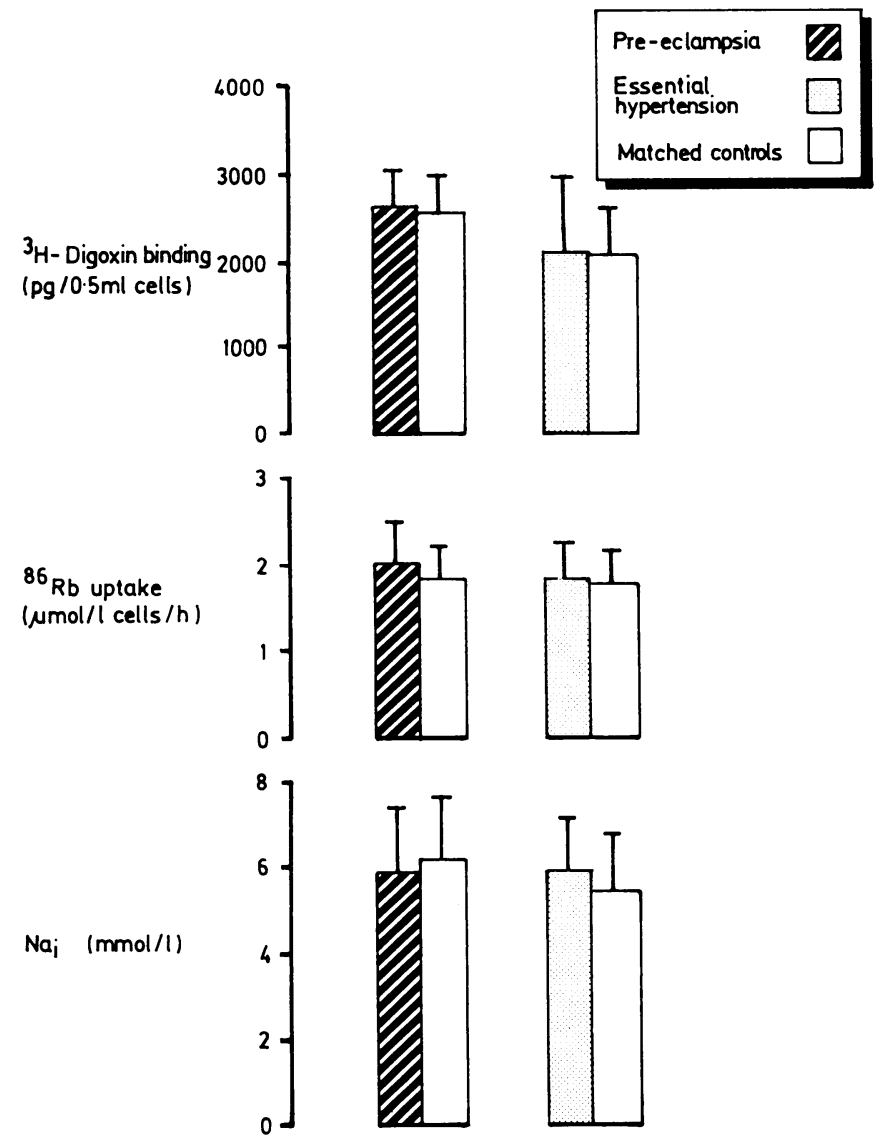

FIG $1-{ }^{3} \mathrm{H}$-Digoxin binding, ${ }^{86} \mathrm{Rb}$ uptake, and intraerythrocytic sodium concentrations $\left(\mathrm{Na}_{\mathrm{i}}\right)$ in women with pre-eclampsia and essential hypertension compared with matched normotensive controls. Bars represent SD.

Conversion: SI to traditional units- ${ }^{86} \mathrm{Rb}: 1 \mu \mathrm{mol} / 1 \approx 8.6 \mu \mathrm{g} / 100 \mathrm{ml}$ $\mathrm{Na}_{\mathrm{i}}: 1 \mathrm{mmol} / \mathrm{l}=1 \mathrm{mEq} / \mathrm{l}$.

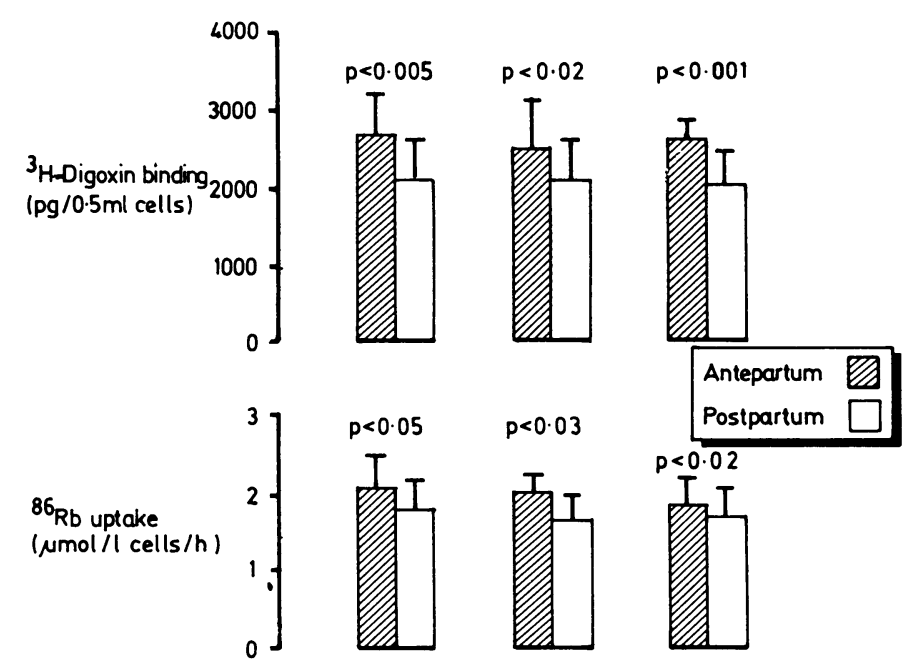

$\mathrm{Na}_{\mathrm{i}}(\mathrm{mmol} / 1)$

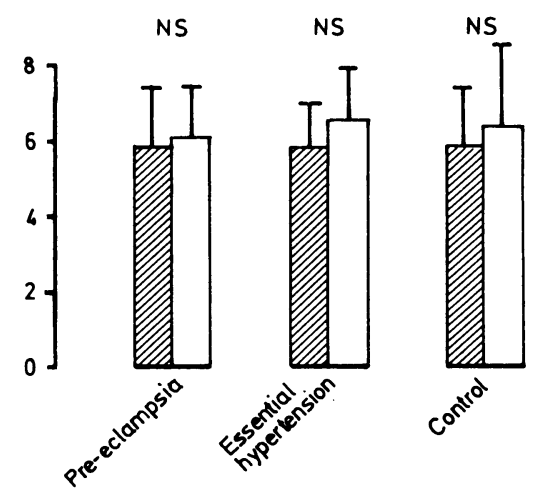

FIG 2-Antepartum and postpartum ${ }^{3} \mathrm{H}$-digoxin binding, ${ }^{86} \mathrm{Rb}$ uptake, and intraerythrocytic sodium concentrations $\left(\mathrm{Na}_{\mathbf{i}}\right)$ in women with pre-eclampsia, essential hypertension, and normal blood pressure. Bars represent SD.

Conversion: SI to traditional units $-{ }^{86} \mathrm{Rb}: 1 \mu \mathrm{mol} / 1 \approx 8.6 \mu \mathrm{g} / 100 \mathrm{ml}$. $\mathrm{Na}_{i}$ : $1 \mathrm{mmol} / \mathrm{l}=1 \mathrm{mEq} / \mathrm{l}$. 
reduction in the intraerythrocytic sodium concentration, these observations suggest that there is an initial increase in intraerythrocytic sodium concentration in pregnancy which in turn leads to adaptive changes in the erythrocyte membrane and a consequent increase in pump numbers and activity. That such adaptive changes occur has been demonstrated both in the erythrocytes of patients taking digoxin and in HeLa cells in experiments in vitro. During short term digoxin treatment, in vitro erythrocytic ${ }^{3} \mathrm{H}$-digoxin binding is reduced owing to occupation of binding sites by the therapeutically administered digoxin, and as a consequence ${ }^{86} \mathrm{Rb}$ uptake by the erythrocytes falls and the intraerythrocytic sodium concentration rises. ${ }^{56}$ During long term treatment, however, the intraerythrocytic sodium concentration returns to pretreatment values, and this is accompanied by a return to pretreatment values of the number of sites available for binding ${ }^{3} \mathrm{H}$-digoxin (even in the presence of the therapeutically administered digoxin) and of the activity of those sites. ${ }^{6} 7$ There may even be an increase in $\mathrm{Na}^{+}, \mathrm{K}^{+}$-adenosine triphosphatase activity during long term digoxin. ${ }^{6}$ Evidence that these adaptive changes during long term treatment may be due to the initial rise in intraerythrocytic sodium concentration comes from the in vitro experiments of Lamb and his colleagues in HeLa cells. Incubation of HeLa cells for 24 hours with low concentrations of ouabain, or with ethacrynic acid, or in a medium containing a low concentration of potassium, causes an increase in the number of ouabain binding sites. ${ }^{8-10}$

All of these procedures raise the intracellular sodium concentration, and the production of binding sites is well related to the intracellular sodium concentration. Lithium, which substitutes for sodium within the cell, also causes an increase in ouabain binding sites. ${ }^{10}$

The lack of change in intraerythrocytic sodium concentration in pregnancy (expressed in $\mathrm{mmol} / \mathrm{l}$ of cells) cannot be explained by a change in intraerythrocytic sodium content accompanied by a concomitant change in red cell volume, since in a separate series of experiments we found no differences in mean red cell volume when comparing pregnant with non-pregnant women (Moore and Redman, unpublished data).

We therefore postulate that the increase in pump numbers and activity occurs as an adaptive response to a need to maintain normal intraerythrocytic sodium concentrations.

There are now beginning to appear reasonably consistent reports on changes in erythrocytic cation transport in pregnancy, although there are a few apparent discrepancies. In 1962 Lowenstein showed that ${ }^{86} \mathrm{Rb}$ uptake by red cells increased by about $45 \%$ during pregnancy, reaching a maximum towards term. ${ }^{11}$ Even by six weeks after delivery ${ }^{86} \mathrm{Rb}$ uptake had not returned to non-pregnant values. This suggests that the differences that we observed between values of both ${ }^{3} \mathrm{H}$-digoxin binding and ${ }^{86} \mathrm{Rb}$ uptake near term and those found six weeks after delivery represent underestimates of the true differences in values between pregnant and non-pregnant values. More recently, Worley et al have reported increased erythrocytic sodiumlithium countertransport during pregnancy, ${ }^{12}$ and since our original report ${ }^{2}$ others have reported increases in erythrocytic glycoside binding. ${ }^{13} 14$ Finally, several groups of workers have found no effect of pregnancy on erythrocytic and leucocytic sodium content or concentrations, ${ }^{15-17}$ although in one study there was a significant decrease in intraerythrocytic content. ${ }^{14}$

So far as the effects of hypertension in pregnancy on transmembrane cation transport are concerned, both we and others $^{12} 141617$ have found similar results in erythrocytic and leucocytic transmembrane cation transport functions when comparing normotensive with hypertensive pregnancies. By contrast, however, Forrester and Alleyne found an increase in intracellular sodium concentration and a decrease in the rate constant for sodium efflux in the leucocytes of women with pre-eclampsia compared with normotensive pregnant women, ${ }^{18}$ while Weissberg et al found that there was an increase in total sodium flux in hypertensive compared with normotensive pregnancy ${ }^{15}$ - a result which contrasts both with the erythrocyte data that we and Worley et al have reported and with the leucocyte data of Forrester and Alleyne. We can find no clear reason for these discrepancies, although they may have been due to technical differences in measurements in vitro or to differences in the matching of control subjects for comparison with hypertensive patients, since cation transport may be altered by a wide variety of other circumstances, including age and race.

JKA acknowledges the support of the Wellcome Trust and the British Heart Foundation, and MPM that of the Medical Research Council of New Zealand.

\section{References}

${ }^{1}$ Anonymous. Essential hypertension-another defect ? [Editorial]. Lancet $1980 ; \mathrm{i}: 1227-9$.

${ }^{2}$ Aronson JK, Moore MP, Redman CWG, Harper C. Sodium-lithium countertransport in erythrocytes of pregnant women. $N \mathrm{Engl} \mathcal{F} \mathrm{Med}$ $1982 ; 307: 1645$

${ }^{3}$ Aronson JK, Grahame-Smith DG, Hallis KF, Hibble A, Wigley F. Monitoring digoxin therapy: I. Plasma concentrations and an in vitro assay of tissue response. Br f Clin Pharmacol 1977;4:213-21.

4 Ford AR, Aronson JK, Grahame-Smith DG, Rose JA. The characteristics of the binding of $12-x^{3} \mathrm{H}$-digoxin to the membranes of intact human erythrocytes: relevance to digoxin therapy. Br $\mathcal{f}$ Clin Pharmacol $1979 ; 8: 115-24$.

5 Ford AR, Aronson JK, Grahame-Smith DG, Carver JG. Changes in cardiac glycoside receptor sites, ${ }^{86}$ rubidium uptake and intracellular sodium concentrations in the erythrocytes of patients receiving digoxin during the early phases of treatment of cardiac failure in regular rhythm and of atrial fibrillation. Br $\mathcal{F}$ Clin Pharmacol 1979;8:125-34.

6 Cumberbatch M, Zareian K, Davidson C, Morgan DB, Swaminathan R. The early and late effects of digoxin treatment on the sodium transport, sodium content and $\mathrm{Na}^{+}, \mathrm{K}^{+}$-ATPase of erythrocytes. Br $\mathcal{F}$ Clin Pharmacol 1981;11:565-70.

7 Ford AR, Aronson JK, Grahame-Smith DG, Carver JG. The acute changes seen in cardiac glycoside receptor sites, ${ }^{86}$ rubidium uptake and intracellular sodium concentrations in the erythrocytes of patients during the early phases of digoxin therapy are not found during chronic therapy: pharmacological and therapeutic implications for chronic digoxin therapy. Br 7 Clin Pharmacol 1979;8:135-42.

${ }^{8}$ Boardman LJ, Lamb JF, McCall D. Uptake of ${ }^{3} \mathrm{H}$-ouabain and Na pump turnover rates in cells cultured in ouabain. 7 Physiol (Lond) 1972;225: 619-35.

${ }^{9}$ Boardman L, Huett M, Lamb JF, Newton JP, Polson JM. Evidence for the genetic control of the sodium pump density in HeLa cells. $f$ Physiol (Lond) $1974 ; 241: 779-94$.

10 Boardman LJ, Hume SP, Lamb JF, Polson J. Effect of growth in lithium on ouabain binding, Na-K-ATPase and $\mathrm{Na}$ and $\mathrm{K}$ transport in HeLa cells. F Physiol (Lond) 1975;244:677-82.

11 Lowenstein JM. Increased rubidium uptake by red cells during pregnancy. Am F Physiol 1962;203:1191-2.

12 Worley RJ, Heutschel WM, Cormier C, et al. Increased sodium-lithium countertransport in erythrocytes of pregnant women. $N$ Engl f $\mathrm{Med}$ $1982 ; 307: 412-6$

${ }^{13}$ Smith JB, Ash KO, Heutschel WM, Worley RJ, Astle CD, Williams RR. Sodium-lithium countertransport in erythrocytes of pregnant women. N Engl F Med 1982;307:1645-6.

14 Rubython J, Morgan DB. The effect of pregnancy and pregnancy induced hypertension on active sodium transport in the erythrocyte. Clin Chim Acta 1983;132:91-9.

15 Weissberg PL, Weaver J, Woods KL, West MJ, Beevers DG. Pregnancy induced hypertension: evidence for increased cell membrane permeability to sodium. $\mathrm{Br} \mathrm{Med} \mathcal{F} 1983 ; 287: 709-11$.

16 MacGillivray I, Campbell DM. The relevance of hypertension and oedema in pregnancy. Clin Exp Hypertens 1980;2:897-914.

17 Kuhnert BR, Kuhnert PM, Murray BA, Sokol RJ. Na/K- and $\mathrm{Mg}$-ATPase activity in the placenta and in maternal and cord erythrocytes of pre-eclamptic patients. Am $\mathcal{f}$ Obstet Gynecol 1977;127:56-60.

18 Forrester TE, Alleyne GAO. Leucocyte electrolytes and sodium efflux rate constants in the hypertension of pre-eclampsia. Clin Sci 1980;59: 199-201S.

(Accepted 15 February 1984) 